\title{
SPOTTING WINNERS IN A WIDE FIELD
}

\author{
Our Highlights section seeks to describe the most important recent research papers. Among the \\ hundreds of drug discovery and development papers published each month, we look particularly \\ for those that have the best chance of really advancing the process.
}

The biggest event of the British racing calendar is the Grand National, run every April by such a large number of horses that most punters who know their game steer well clear of trying to pick a winner. It's a spectacle, rather than a good place to do business. Faced with a rather similar overabundance of choice, every month, in our Highlights section, we seek to turn the spotlight onto the best recent papers in drug discovery, briefly and simply explaining their findings and relevance. Hopefully, our methods for picking papers are more rigorous than those of the average tipster. So how do we choose what to highlight?

It is hard to define what limits to set to the field of 'drug discovery'. With practically every other paper in biomedical science containing the almost obligatory final sentence suggesting the therapeutic relevance of the molecule or system under study, it sometimes seems that almost everything falls within this remit. Clearly, even those studies that seem unrelated to drugs might impact the discovery of new therapeutics in some unforeseen way. Certainly, papers published across a wide array of journals, on many different topics, form the backdrop to the discovery of new drugs. Our task is to sift out those studies that are actually most likely to advance the process, rather than those that indicate the vague possibility of an advance.

By our definition, drug discovery covers everything from basic disease mechanisms and the chemistry and screening that accompany the discovery and optimization of lead compounds, through to the preclinical and clinical testing of new drug candidates. We believe that this integrated approach mirrors the new drive for integration of resources seen throughout the industry, in which improving the success rate is thought by many to be crucially dependent on facilitating communication between different sectors of the pipeline, so that people working in different disciplines can regularly trade ideas. For instance, getting the right drug candidates into animal models depends on having chemists working closely with biologists, and the success rate of taking those candidates into studies in humans is likely to improve only if clinicians and basic scientists are talking the same language. For that reason, although no doubt annoying some specialists with our lack of detail, we try to keep our Highlights accessible to all who might be interested.

Although each specialization within the discovery pipeline has its own particular view of what constitutes the most important research, most agree that there is a special sort of applied science that leads most effectively to drugs. Difficult to describe without reference to examples, such studies tend to be interdisciplinary, requiring an overview of the 'bigger picture', and, importantly, often do not involve momentous shifts in the body of scientific knowledge. Rather, they tend to be incremental, bringing together known observations and techniques in new and unexpected ways. Indeed, the very beauty of many of these studies is that they are directed towards an application, rather than being isolated observations.

So, these are our criteria. To help us sift through the sea of relevant journals, we have a Highlights Advisory Panel (who are listed on page 329) with hugely diverse expertise. We aim to keep as up to date as possible, concentrating on studies published within the last couple of months. Done properly, collecting this work together can serve a strong scientific purpose. With drug discovery failing to deliver the necessary numbers of compounds into the development pipeline (see the article on page 335 for another reminder of this), and some pessimistic financial analysts suggesting that present growth rates within the industry are unsustainable, now is a good time for introspection. Highlighting the very best of modern drug discovery, albeit only a fraction of the best, with the aim of showing how this research should be done, is, of course, the founding principle behind Nature Reviews Drug Discovery. And if you were hoping for a one-sentence definition of what we highlight, then perhaps, as one of our panel suggests, it should simply be: "I wish I'd thought of that". 